\title{
Level of 25(Oh)D Serum, Expression of Interleukin 4 and Glucocorticoid Receptor of Mononuclear Cell in Steroid Resistance Nephrotic Syndrome Children
}

\author{
Vonny Mariany Deckert ${ }^{1}$, Krisni Subandiyah ${ }^{2 *}$, Loeki Enggar Fitri ${ }^{3}$
}

\author{
${ }^{1}$ Magister Program in Biomedical Sciences, Faculty of Medicine, University of Brawijaya Malang \\ ${ }^{2}$ Department of Pediatric, Saiful Anwar General Hospital, Malang \\ ${ }^{3}$ Department of Parasitology, Faculty of Medicine, University of Brawijaya Malang
}

\begin{abstract}
Nephrotic syndrome (NS) is an autoimmune disease and its steroid resistance status supposed correlate with 25(OH)D level and IL-4 expression. The aimed of this study was investigated 25(OH)D plasma level, IL-4 and GR expression of PBMC in steroid sensitive and resistant pediatric NS patients and the association of those parameters. 27 subjects were divided into three groups (control group, steroid resistant NS group, and steroid-sensitive NS group). Peripheral blood mononuclear cells (PBMCs) isolated using the Ficoll-Hypaque method. Plasma $25(\mathrm{OH}) \mathrm{D}$ level was measured using ELISA method. IL-4 and GR expression were measured using flow cytometry of PBMCs. This study showed that 25(OH)D level and GR expression were significantly different in the control group compared to steroid resistant NS group ( $\mathrm{p}<0.05)$. Plasma 25(OH)D level, IL-4, and GR expression were not correlated each other in NS patients ( $\mathrm{p}>0.05)$. Plasma 25(OH)D level, IL-4 and GR expression were not contributed to steroid resistance in NS patients. However, GR expression has the highest contribution to steroid resistance of NS patient (Wald score 1.198). Plasma 25(OH)D level and GR expression were lower in steroid resistant NS group. GR expression has the highest contribution in steroid resistance of NS patients.
\end{abstract}

Keywords: 25(OH)D level, GR expression, IL-4 expression

\section{INTRODUCTION}

Nephrotic syndrome (NS) defined as a glomerular disease that characterized by proteinuria, edema, and hypoalbuminemia. This disease could affect all ages, especially 2-6 years old child with male: female ratio [1]. Nephrotic syndrome occurred 2-7 new case per 100.000 children [2]. Previous data had been reported that there was 101 case (34\%) idiopathic NS from total 297 nephrology disease at Pediatric Department of Saiful Anwar Hospital [3].

Idiopathic NS is an autoimmune mediated disease that both steroid sensitive and steroid resistant possessed $\mathrm{T}$ cell dysfunction, decreased of 25(OH)D level, and glucocorticoid receptor (GR) expression. Nephrotic syndrome caused by an imbalance of Th1 and Th2 cytokines that could trigger podocyte dysfunction and massive proteinuria [4]. IL-4 and IL-13 could induce proteinuria in idiopathic NS patient [5].

\footnotetext{
${ }^{*}$ Corresponding author:

Krisni Subandiyah

Department of Pediatric, Saiful Anwar General Hospital,

Malang, Indonesia

Email: krisdika2002@yahoo.com
}

A previous study showed that glucocorticoid receptor (GR) expression increase in the remission stage of NS and decreased GR expression in steroid resistant NS compared with steroid sensitive NS [6]. Furthermore, GR expression negatively correlated with histopathological damage of glomerulus [7].

$25(\mathrm{OH}) \mathrm{D}$ level in NS patients also decrease caused by renal function impairment. Takeda has been described that an active form of vitamin D3 could modulate the immune response [8]. Vitamin D3 could reverse GR downregulation induced by ligand through its interaction with GC signaling pathway [8]. The role of vitamin D3 in immune response had been studied in steroid resistant asthmatic patients. A study showed that administration active form of vitamin D3 could increase IL-4, IL-5, IL-13 expression by Th2 and IL-10 and TGF by Treg [9].

Previous study showed enhancement of various cytokines production such as IL-1 IL-2, IL-4 and TNF- $\alpha$, and also decreased of IL-10 production in minimal changes NS patient's peripheral blood mononuclear cells (PBMC) [10].

Its immunomodulatory effects of vitamin D could 
suppress Th1: IFN-V; IL-2; Th17: IL-17 IL-1; IL-6; TNF- $\alpha$; IL-12; IL-23 secretion, suppression of Treg: IL10; TGF- $\beta$ and also enhancement of Th2: IL-4; IL-5; IL-13 secretion [11]. In other hands IL-4 and IL-2 decrease GR $\alpha$ without affect GR $\beta$, which further concluded that steroid resistance induced by IL-4 and IL-2 and marked by decreased expression of GR $\alpha$ [12].

This study was conducted to investigate $25(\mathrm{OH}) \mathrm{D}$ plasma level, IL-4 and GR expression of PBMC in steroid sensitive and resistant pediatric NS patients and their association.

\section{MATERIALS AND METHODS Study Design}

This study was cross-sectionally designed to measure vitamin D (25(OH)D) plasma level, GR and IL-4 expression of PBMC in steroid sensitive NS, steroid resistant NS, and control group. This study was conducted in nephrology policlinic and ward of Pediatric Department, Dr. Saiful Anwar Hospital Malang, and Biomedical Laboratory, Faculty of Medicine, Brawijaya University Malang. This study had been approved by Ethical Committee of Medical Faculty of Medicine, Brawijaya University.

\section{Population and Subject}

Research subject included in this study was nine subjects in each group. Inclusion criteria of topics are classified as steroid sensitive and steroid resistant NS aged 1-14 years old and allowed by his/her parents to join in this study (informed consent). Exclusion criteria of subjects is NS which classified as secondary NS (caused by extra-renal factor such as chemical/drugs, systemic disease such as SLE or Henoch Schonlein, infectious disease such as malaria, hepatitis), congenital/infantile NS, patient with autoimmune disease (SLE, DM), patient with allergy (asthma, rhinitis, atopic dermatitis), patients with severe infection, liver dysfunction, and patient with vitamin D supplementation.

\section{PBMC Isolation}

Blood sample in Vacutainer EDTA/heparin mixed properly, and then mixed with PBS (1:1). Blood sample-PBS take using micropipette and then overlaid to falcon tube which already contains Ficoll-Hipaque $\mathrm{d}=1.077 \mathrm{~g} / \mathrm{mL}$ through its wall (volume sample: FicollHipaque 1:1). This mixture then centrifuged at room temperature $1000 \mathrm{rpm}$ for $30 \mathrm{~min}$. After centrifuged, this mixture will form 4 layer (plasma, PBMC, FicollHipaque, and granulocyte or erythrocyte). PBMC ring has taken slowly using micropipette and then placed in new $15 \mathrm{~mL}$ centrifuge bottle. PBMC solution and then washed with PBS $10 \mathrm{~mL}$ and centrifuged at room temperature, $1200 \mathrm{rpm}$ for $10 \mathrm{~min}$. Pellet washed again with $\mathrm{PBS}$ and then centrifuged at room temperature, $1200 \mathrm{rpm}$ for $10 \mathrm{~min}$ (this process is repeated two times). PBMC formed as a pellet in the bottom of the bottle.

\section{Measurement of GR Expression in $C D 3$}

PBMC's pellet was added with PE-conjugated antihuman CD357 (GITR) antibody (catalog number 311604) and then incubated for $15 \mathrm{~min}$ in the dark room. After that, the pellet was centrifuged at 2500 rpm for $3 \mathrm{~min}$. Then, the pellet was added to one $\mathrm{mL}$ fixation buffer solution in each tube, centrifuged at $2500 \mathrm{rpm}, 4^{\circ} \mathrm{C}$ for $3 \mathrm{~min}$. The supernatant was removed. Cell pellet that has been fixated then resuspended by added $1 \mathrm{x}$ permeabilization washed buffer and centrifuged at $2500 \mathrm{rpm}, 4^{\circ} \mathrm{C}$ for $3 \mathrm{~min}$. After this process, the cell pellet was resuspended in added $0,5 \mathrm{ml}$ cell staining buffer and then analyzed using flow cytometry. Expression of GR analyzed using software BD Cell Quest Pro.

\section{Measurement of IL-4 Expression}

PBMC's pellet was added with PerCP/Cy5.5 antihuman IL-4 (catalog number MP 4-25D2) and then incubated in the dark room for $15 \mathrm{~min}$. After that, the pellet was added to $1 \mathrm{~mL}$ cell staining buffer and then centrifuged for $3 \mathrm{~min}$ at Mystral-1000 rt and hatch centrifuge at $2500 \mathrm{rpm}$, room temperature continuously. Supernatant was removed, then added with $1 \mathrm{ml}$ fixation buffer, incubated for $15 \mathrm{~min}$ in dark room, room temperature, and centrifuged for $3 \mathrm{~min}$ in Mystral-1000 rt and hettch centrifuge at $2500 \mathrm{rpm}$ at room temperature continuously.

The supernatant was removed, the pellet was added with permeable wash buffer and then incubated for 15 min in a dark room at room temperature. After this process, centrifuged again for $3 \mathrm{~min}$ in Mystral-1000 rt and hatch centrifuge at $2500 \mathrm{rpm}$ at room temperature continuously. The supernatant was removed, and the pellet was added with cell staining buffer $500 \mu \mathrm{l}$, and then placed in a sample tube for flow cytometry machine, BD Facs Calibur. IL-4 expression analyzed using software BD Cell Quest pro.

\section{Measurement of Plasma 25(OH)D Level}

Three polypropylene tube that used for control, sample, and calibrator were prepared. $1 \mathrm{ml} 25$-D biotin 
solution was added to all tube, and then vortex for 10 seconds. Each of calibrator dilution added $200 \mu \mathrm{l}$, control or sample in each appropriate well according to an antibody-coated plate/microplate. The plate was covered with plastic and then incubated in $18-25^{\circ} \mathrm{C}$ for two hours. All well then washed three times using wash solution. $200 \mu \mathrm{l}$ conjugate were added to each well using multichannel pipette. Plate covered again with plastic, incubated in $18-25^{\circ} \mathrm{C}$ for 30 min (this process repeat 2 times). $200 \mu \mathrm{l}$ TMB substrate was added into each well, and then covered with plastic, incubated in $18-25^{\circ} \mathrm{C}$ for 30 minutes. $100 \mu \mathrm{l}$ stop solution was added to each well. Absorbance was measured in each well at $450 \mathrm{~nm}$ using microplate reader in $30 \mathrm{~min}$ after added stop solution.

\section{RESULTS AND DISCUSSION Characteristics of Subjects}

This study involved 27 subjects divided into three groups: control group, steroid resistant NS group, and steroid-sensitive NS group. The subject characteristic such as sex, age, nutrition status described in Table 1 .

\section{Level of Plasma 25(OH)D}

Figure 1 showed 25(OH)D level was $23.86 \mathrm{ng} / \mathrm{mL}$ for the control group, $15.50 \mathrm{ng} / \mathrm{mL}$ for steroid sensitive NS group, and $10.88 \mathrm{ng} / \mathrm{mL}$ for steroid-resistant NS group. One way ANOVA showed significant differences between groups $(p<0.05)$. Post Hoc Tukey test showed significant differences between the control group and steroid resistant group $(\mathrm{p}=0.003)$.

\section{IL-4 Expression}

Figure 2 showed IL-4 expression was $2.89 \%$ for the control group, $0.86 \%$ for steroid-resistant NS group, and $1.09 \%$ for steroid-sensitive NS group. Non-parametric test Kruskal-Wallis showed no significant differences among groups $(\mathrm{p}=0.095)$.

\section{GR Expression}

Figure 3 showed GR expression was 3.86\% for the control group, $1.74 \%$ for steroid-resistant NS group, and $2.66 \%$ for steroid-sensitive NS group. One way ANOVA showed significant differences between groups $(p<0.05)$. Post Hoc Tukey test showed significant differences between the control group and steroidresistant group $(\mathrm{p}=0.008)$.

\section{Correlation of Plasma 25(OH)D Level, IL-4 and GR Expression}

Pearson correlation test showed no significant cor- relation between 25(OH)D level and IL-4 expression $(\mathrm{p}>0.05, \mathrm{r}=0.382), 25(\mathrm{OH}) \mathrm{D}$ level and GR expression ( $\mathrm{p}>0.05, \mathrm{r}=0.417), \mathrm{IL}-4$ expression and GR expression $(\mathrm{p}>0.05, \mathrm{r}=0.271)$. Logistic regression test showed 25(OH)D level, IL-4 expression, and GR expression has no significant contribution for steroid resistance. However, from 3 parameters, GR expression has highest Wald score (1.198) which mean GR expression is the most significant predictor for steroid resistance in NS patients.

\section{Characteristics of Subjects}

Data showed a range of patient age was 5-10 years old for steroid sensitive NS, 10-14 years old for steroidresistant NS. This result consistent with the previous study reported that $75 \%$ NS aged less than 10 (ten) years old [2].

This study showed in NS groups dominated by the female. Epidemiological data showed in children aged younger than 8 (eight) years old at the onset of disease, male: female ratio varied from 2:1 until 3:2. However, in older children, male: female ratio almost same. Other data indicated that $66 \%$ patients with MCNS (minimal changes nephrotic syndrome) or FSGS (focal segmental glomerulosclerosis) was male, but $65 \%$ patients with MPGN was female [16]. Berg and Wening [10] speculated that a higher prevalence of NS in the male might be correlated with abnormal $\mathrm{T}$ cell clone that frequently occurred in thymus gland [10].

Nutritional status showed in all three groups has good nutrition status. NS patients possessed higher risk factor for developmental impairment caused by NS itself or its complication [13].

\section{Plasma 25(OH)D Level, IL-4 and GR Expression}

Data showed that plasma $25(\mathrm{OH}) \mathrm{D}$ level in the control group significantly higher than NS groups.

Table 1. Characteristic of subject

\begin{tabular}{llll}
\hline Characteristics & $\begin{array}{l}\text { Control } \\
(\mathbf{n}=9)\end{array}$ & $\begin{array}{l}\text { S S N S } \\
(\mathbf{n}=9)\end{array}$ & $\begin{array}{l}\text { S R N S } \\
(\mathbf{n = 9})\end{array}$ \\
\hline a Age (year) & & & \\
$1-\leq 5$ years old & $0(0 / 9)$ & $2(2 / 9)$ & $1(1 / 9)$ \\
$5-\leq 10$ years old & $5(7 / 9)$ & $5(5 / 9)$ & $2(2 / 9)$ \\
$10-14$ years old & $4(4 / 9)$ & $2(2 / 9)$ & $6(6 / 9)$ \\
\hline b. Sex & & & \\
- Male & $1(1 / 9)$ & $4(4 / 9)$ & $3(3 / 9)$ \\
- Female & $8(8 / 9)$ & $5(5 / 9)$ & $6(6 / 9)$ \\
\hline c. Nutritional St at & & & \\
- Over-nutrition & $2(2 / 9)$ & $1(1 / 9)$ & $0(0 / 9)$ \\
- Good-nutrition & $9(7 / 9)$ & $7(7 / 9)$ & $8(8 / 9)$ \\
- Under-nutrition & $0(0 / 9)$ & $1(1 / 9)$ & $1(1 / 9)$ \\
- Malnutrition & $0(0 / 9)$ & $0(0 / 9)$ & $0(0 / 9)$ \\
\hline
\end{tabular}




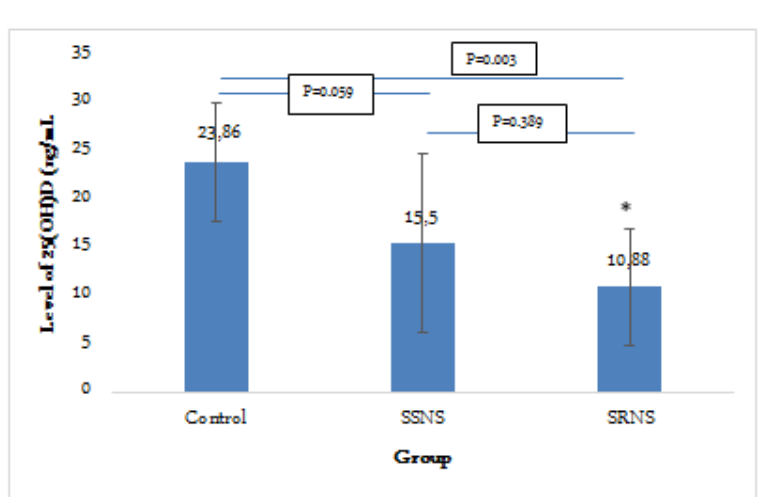

Figure 1. Mean of Plasma 25(OH)D level $(\mathrm{ng} / \mathrm{mL})$ in control, steroid resistant NS, and steroid-sensitive NS group. * Post Hoc Tukey showed significant differences with the control group.

Furthermore, a post hoc test showed that plasma $25(\mathrm{OH}) \mathrm{D}$ level significantly different between a control group and steroid-resistant group, but no significant differences between steroid-resistant and steroid-sensitive groups. This results indicated that vitamin $\mathrm{D}$ has a role in the development of NS. However, because of limitation of study design (observational), we cannot conclude whether vitamin D caused NS or NS caused vitamin $\mathrm{D}$ dysfunction. This result also indicated that vitamin $\mathrm{D}$ might be a role for steroid resistance in NS patient.

Cheng et al. [14] reported that dexamethasone combined with vitamin D3 protect podocyte from experimental injury. Colin et al. [15] showed that $1,25(\mathrm{OH}) 2 \mathrm{D} 3$ could inhibit tumor necrosis factor (TNF), interleukin-17 (IL-17) and interferons (IFN) production, and also triggered IL-4, IL -5, and IL-10 expression in PBMC or CD4T-cell.

Calcitriol administration in $\mathrm{T}$ cell culture could inhibit proinflammatory cytokine production in Th1, Th9, and Th22 and enhance production of anti-inflammatory cytokines in Th2. Clinically, 1,25(OH)2D3 has the beneficial effect of reducing proteinuria and altered renin-angiotensin-aldosterone (RAAS) system. Histopathologically, 1,25( $\mathrm{OH}) 2 \mathrm{D} 3$ could preserve the structural and functional integrity of podocytes and also suppress renin expression directly in transcriptional stage [16].

This study also showed that IL-4 expression lower in the control group compared with NS group and significantly different with steroid resistant NS group. This data indicated that NS group showed activation of Th2-cells. Kanai described that in NS occurred imbalance of Th1 and Th2 ratio whereas Th2 more dominant and cause increased expression of IL-4 and IL-13
[17]. In relapse NS, activated T cell induce IL-4 and IL-13 secretion, which in turn triggered IgE isotype switching [17].

Higher IgE group showed increased of IL-4 and IL-5 expression significantly [25]. [25] further explains that increased of IL-4 and IL-5 production in idiopathic NS could indicate several cytokines involved in $\operatorname{IgE}$ production. Allergic treatment with single agent could not induce NS remission, suggested that increased of IgE did not cause NS, but reflected allergic response toward their humoral immunity perturbation $[10,25,26]$.

Pan et al. and [18] consistently agree with $\mathrm{Hafez}$ [4] about imbalance of Th1/Th2 and domination of Th2 response in NS $[4,18,27]$. In MCNS, there was an increased of IL-4, IL-8 and GRO- $\gamma$ (growth regulated protein) production. IL-8 caused altered permeability of glomerular basement membrane (GBM) through a production of HSPGs (Heparan Sulfate Proteoglycans) which in turn could induce proteinuria in a rat model. The IL-4 and IL-13 receptor also found in podocytes and enhanced expression of both receptors found in MCNS. Overexpression of IL-13 in the animal model caused podocyte damage through transduction signal and activation of the transcriptional pathway. However, the role of IL-4 in podocyte damage still can not be understood [4].

In this study, lower expression of IL-4 in NS groups might be caused by administration of glucocorticoid and cytostatic drugs. The subject included in this study has been a routine visit to pediatric nephrology policlinic and hospitalized for cytostatic drugs therapy. Because of this, IL-4 expression mean still did not reflect steroid resistant NS, which newly diagnosed. Cytostatic drugs that act in $\mathrm{T}$ lymphocyte and usually used in NS is cyclophosphamide, chlorambucil or cyclosporine. Cyclophosphamide and chlorambucil are alkylating agents and cross-linked DNA during all cell

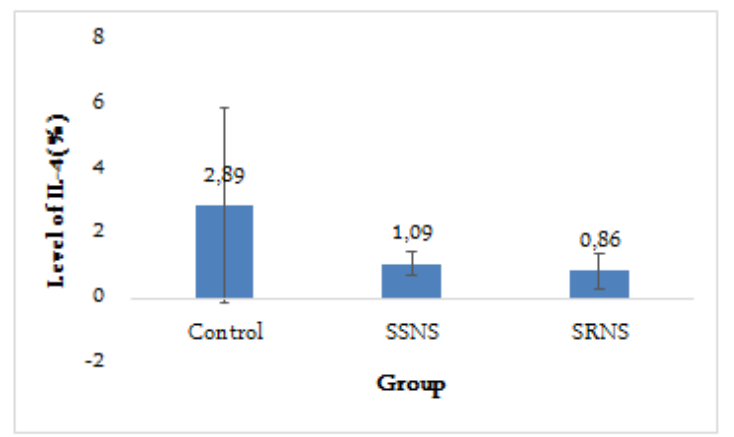

Figure 2. Mean of PBMC's IL-4 expression (\%) in control, steroid-resistant NS, and steroid-sensitive NS group. 


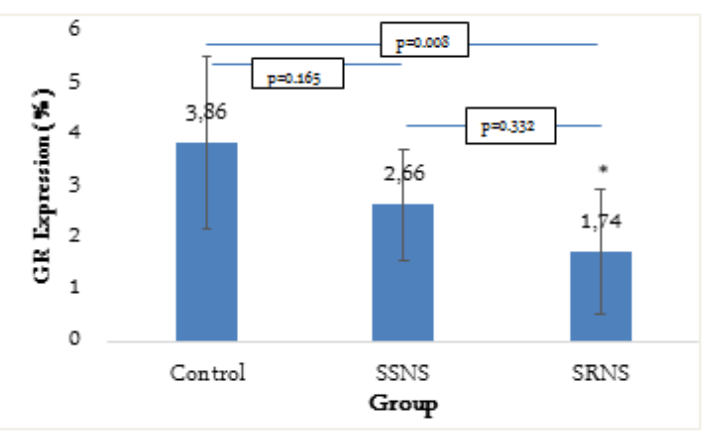

Figure 3. Mean of PBMC's GR expression (\%) in control, steroid-resistant NS, and steroid-sensitive NS group. ${ }^{*}$ Post Hoc Tukey showed significant differences with the control group.

cycle phase. Cyclosporine is calcineurin inhibitor that blocked the production of several cytokines such as IL2, IL-3, IL-4 and interfered IL-2 receptor expression (CD25) which in turn prevent $\mathrm{T}$ cell activation [20].

Other possible cause-related with the role of Th1/Th2 ratio in the pathogenesis of NS. Glucocorticoid treatment could change Th1/Th2 ratio through suppression of proinflammatory cytokines and induced of anti-inflammatory cytokines as described by Barnes (2010) [19]. Barnes stated that GC treatment could trans-repressed inflammatory cytokines (IL-2, IL-3, IL4, IL-5, IL-6, IL-23, IL-15, TNF- $\alpha$, GM-CSF, SCF, TSLP); chemokines (CCL1, CCL5, CCL11, CXCL8); inflammatory enzymes: iNOS (inducible nitric oxide synthase), COX-2 (inducible cyclo-oxygenase), cPLA2 (inducible phospholipase A2); inflammatory peptides (endothelin-1); mediator receptor: NK1 (neurokinin), bradykinin (B2)-receptor; adhesion molecules (iCAM1, VCAM-1) and also trans-activated lipocortin-1; B2Adrenoceptors; Secretory leukocyte inhibitory protein; IKB- $\alpha$ (inhibitor NF-KB); MKP1 (inhibitor MAP kinase); Glucocorticoid inducible leucine zipper (GILZ); anti-inflammatory cytokines or inhibitor: IL-10, IL-12, IL-1 receptor antagonist [19].

This study also showed lower GR expression in steroid-resistant NS group compared with control and steroid-sensitive NS group. Among three variables, GR has the highest contribution to steroid resistance in NS patients. This data are consistent with the previous study conducted by [21] which reported that GR density in peripheral $\mathrm{T}$ cell was important factor determined GC sensitivity. GR expression could be used as the predictor for steroid responsivity rate in adult MCNS [28]. Wasilewska et al. [6] stated that lower expression of GR caused a worse response to GC treatment. Carlotti et al. [22] showed that GR might be mediated the occurrence of glucocorticoid resistance in idiopathic NS.

Other study showed that autoregulation of GR was not related with GC response in idiopathic NS patients [23]. GC sensitivity depends on functionality and expression of its receptor. GR expressed almost in all cells, include convoluted distal tubule cells, collecting duct cells, and all part of glomerular cells. GC cellular response directly correlated with the hormone-binding capacity [24].

This study was designed as observational (cross-sectional) that has a limitation in investigating the causal effects. Because of that, we suggested to do further research which developed experimentally both in vivo or in vitro to investigate the role of IL-4, vitamin $\mathrm{D}$, and GR in NS (especially in newly diagnosed steroid resistant NS patients and focused on Th1/Th2 ratio). Further investigation in GR isomer (GR $\alpha$ and GR $\beta)$ and their role in steroid resistance of NS should be performed. Development knowledge in the pathophysiology of steroid resistance especially in NS could be followed by the development of drugs targeting in molecules that act as the predictor in steroid resistance.

\section{CONCLUSIONS}

We conclude that plasma $25(\mathrm{OH}) \mathrm{D}$ level, IL-4 and GR expression was lower in steroid resistant NS group. GR expression has the highest contribution to steroid resistance of NS patients.

\section{ACKNOWLEDGMENT}

We would like to thank the Departement of Child Health, Faculty of Medicine, University of Brawijaya/dr. Saiful Anwar General Hospital, Malang, Indonesia for providing the grant to accomplish this research. We also thank Wahyuda Ngatiril Lady S.Si, from Biomedical of Medical Faculty, Brawijaya University for his excellent assistance in flow cytometry.

\section{REFERENCES}

1. Davin J-C, Rutjes NW (2011) Nephrotic Syndrome in Children: From Bench to Treatment. Int J Nephrol. 372304.

2. Roth KS, Amaker BH, Chan JCM (2002) Nephrotic Syndrome: Pathogenesis and Management. Pediatr Rev 23: 237-47.

3. Krisni (2007) Pola penyakit ginjal pada anak di RS Saiful Anwar Malang tahun 2002-2006. Disampaikan pada Pertemuan Ilmiah Tahunan Ilmu Kesehatan Anak Ikatan Dokter Anak Indonesia (PIT IKA-IDAI), Yogyakarta. 
4. Hafez MA, Shimada M, Lee PY, Johnson RJ, Garin EH (2009) Idiopathic Nephrotic Syndrome and Atopy: Is There a Common Link?, American Journal of Kidney Diseases. 54(5): 945-53.

5. Araya C, Diaz L, Wasserfall C, Atkinson M, Mu W, Johnson R, Garin E (2009) T regulatory cell function in idiopathic minimal lesion nephrotic syndrome. Pediatr Nephrol. 24(9): 1691-8.

6. Wasilewska A, Zoch-Zwierz W, Tomaszweska B, Wiercinski R, Stasiak-Barmuta A (2003) Expression of Glucocorticoid Receptors in Mononuclear Cells in Nephrotic Syndrome. Pediatr Nephrol. 18(8): 778-82.

7. He XJ, Yi ZW, Dang XQ, Zhang HQ, He QN, Mo SH, Bai HT, Geng WM, Yang HB (2005) Effect of glucocorticoid on glucocorticoid-resistant children with primary nephrotic syndrome. Zhonghua Er Ke Za Zhi. 43(2): 10912.

8. Takeda M, Yamashita T, Sasaki N, Nakajima K, Kita T, Shinohara M, Ishida T Hirata K (2010) Oral Administration of an Active Form of Vitamin D3 (Calcitriol) Decreases Atherosclerosis in Mice by Inducing Regulatory $\mathrm{T}$ Cells and Immature Dendritic Cells With Tolerogenic Functions. Arterioscler Thromb Vasc Biol. 30: 2495-503.

9. Mathieu C (2011) Vitamin D and the immune system: Getting it right. IBMS BoneKEy. 8: 178-186.

10. Berg JG, Weening JJ (2004) Role of the immune system in pathogenesis of idiopathic nephrotic syndrome. Clinical Science. 107: 125-36.

11. Song Y, Hong J, Liu D, Lin Q, Lai G (2013) 1,25-dihydroxyvitamin D3 inhibits nuclear factor kappa B activation by stabilizing inhibitor IKB $\alpha$ via mRNA stability and reduced phosphorylation in passively sensitized human airway smooth muscle cells. Scand J Immunol. 77: 109-16.

12. Vazquez-Tello A, Halwani R, Hamid Q, Al-Muhsen S (2013) Glucocorticoid receptor-beta up-regulation and steroid resistance induction by IL-17 and IL-23 cytokine stimulation in peripheral mononuclear cells. J Clin Immunol. 33(2): 466-78.

13. Eddy AA, Symons JM (2003) Nephrotic syndrome in Childhood. Lancet. 362: 629-39.

14. Cheng X, Zhao X, Khurana S, Bruggeman LA, Kao HY (2013) Microarray Analyses of Glucocorticoid and Vitamin D3 Target genes in Differentiating Cultured Human Podocytes. PloS ONE. 8: 1-11.

15. Colin EM, Asmawidjaja PS, Van Hamburg JP, Mus AMC, Van Driel M, Hazes JMW, Van leeuwen JPTM, Lubberts E (2010) 1,25-Dihydroxyvitamin D3 Modulates Th17 polarization and interleukin-22 expression by Memory $\mathrm{T}$ Cells From patients with Early Rheumatoid arthritis.
Arthritis \& Rheumatism. 62: 132-42.

16. Lang CL, Wang MH, Chiang CK, Lu KC (2014) Vitamin $\mathrm{D}$ and the Immune System from the Nephrologist's Viewpoint. ISRN Endocrinology. 2014: 1-1.

17. Kanai T, Shiraishi H, Yamagata T, Ito T, Odaka J, Saito $\mathrm{T}$, et al. (2010) Th2 cells predominate in idiopathic steroid-sensitive nephrotic syndrome. Clin Exp Nephrol. 14: $578-83$.

18. Bhimma R (2014) Steroid sensitive nephrotic syndrome in children. J. Nephrol Therapeutic. S11: 003.

19. Barnes PJ (2010) Glucocorticosteroids: current and future directions. BJP. 163: 29-43.

20. Brogan PA, Dillon MJ (2000) The use of immunosuppresive and cytotoxic drugs in non malignant disease. Arch Dis Child. 83: 259-264

21. Coutinho AE, Chapman KE (2011) The anti-inflammatory and immunosuppressive effects of glucocorticoids, recent developments and mechanistic insights. Molecuar and Cellular Endocrinology. 335: 2-13.

22. Carlotti P, franco PB, Ellas LL, fancicani I, Costa C, Foss N, Moreira AC, Castro M (2004) Glucocorticoid receptors, in vitro sensitivity, and cytokine secretion idiopathic nephrotic syndrome. Kidney Int. 65: 403-8.

23. Chen P, Jiang T, Ouyang J, Cui Y (2011) Glucocorticoid receptor autoupregulation and its relation with glucocorticoid sensitivity in idiopathic nephrotic syndrome. Int Urol Nephro. 43: 167-74.

24. Gross KL, Lu NZ, Cidlowski JA (2009) Molecular mechanisms regulating glucocorticoid sensitivity and resistance. Mol Cell Endocrinol. 300: 7-16.

25. Youn YS, Lim HH, Lee JH (2012) The Clinical Characteristics of Steroid Responsive Nephrotic Syndrome and Children according to the Serum Immunoglobulin E Levels and Cytokines. Yonsei Med J. 53(4): 715-722.

26. Fuke Y, Endo M, Ohsawa I, Satomura A, Hidaka M, Fujita T, Ohi H (2002) Implication of Elevated Serum IgE Levels in Minimal Change Nephrotic Syndrome. Nephron. 91: 769-770.

27. Pan QJ, Wu J, Tao J, Chen Y, Li L, Deng Z, Liu W, Liu $\mathrm{H}$ (2014) Role of Basophils in the Pathogenesis of Minimal Change Nephrotic Syndrome: A Literature Review. Exp Ther Med. 8(4): 1027-1031.

28. Han SH, Park SY, Li JJ, Kwak SJ, Jung DS, Choi HY, Lee JE, Moon SJ, Kim DK, Han DS, Kang SW (2008) Glomerular Glucocorticoid Receptor Expression is Reduced in Late Responders to Steroids in Adult-onset Minimal Change Disease. Nephrol Dial Transplant. 23(1): 16975 . 